\title{
Haemangiosarcoma of breast
}

\author{
E. KESSLER AND I. L. KOZENITZKY \\ From the J. Casper Department of Pathology, Beilinson Hospital, Tel-Aviv University Medical School, \\ Petah-Tiqva, Israel
}

SYNOPSIS This is a report of a haemangiosarcoma involving the breast, spleen, liver, lungs, and subcutaneous tissue. There appears to be evidence that the tumour arose in the breast with theo other sites representing metastases rather than a malignant transformation of multiple haeman $\tilde{w}_{\mathrm{O}}$ giomatoses. Histologically the primary breast tumour appeared deceptively innocuous.

Primary haemangiosarcoma of the breast is an uncommon tumour, which occurs more frequently in young women, although older age groups are not exempt (Steingaszner, Enzinger, and Taylor, 1965). These tumours have the worst prognosis of all malignant tumours of the breast (McDivitt, Steward, and Berg, 1968), despite the primary lesion's possibly having a deceptively benign histological appearance (Mackenzie, 1961; Steingaszner et al, 1965), Metastases occur early through the blood stream and a short clinical course is common. In different series the time from the onset of symptoms to death has varied from 1.6 to 2.6 years (Mackenzie, 1961; McClanahan and Hogg, 1954; Steingaszner et al,1965).

Several names have been applied to this tumourbenign metastasizing haemangioma, angiosarcoma, haemangioendothelioma, haemangiosarcoma (Steingaszner et al, 1965).

In all, 42 haemangiosarcomas have been reported since 1907 (Gulesserian and Lawton, 1969).

\section{Case Report}

The patient, a 57-year-old married woman without children, had a firm nodular lump removed from the right breast in January 1966. The nodule was first noticed some months previously and had been slowly enlarging since. The tumour was histologically diagnosed as a benign haemangioma. In October 1967 the patient was admitted with a recurrent mass of the right breast and a subtotal mastectomy was performed. Histological findings were again interpreted as benign haemangioma. In March 1968 the patient was readmitted with a recurrent tumour in the scar of the previous operation. A wide excision was performed. During 1969 the patient Received for publication 26 November 1970. was readmitted several times with further tumours, one in the left breast, a second in the abdomina足 wall, a third in the left shoulder, and a fourth in the right side of the forehead. These tumours were considered to be metastases and the patient wase treated by radiotherapy and later by chemotherapy (nitrogen mustard $5.3 \mathrm{mg} \times 4$ ). In January 1970 radioactive gold and Indium scanning was per-s formed, but no signs of hepatic involvement coulde be detected.

The patient's general condition continued too deteriorate and she was readmitted in April 1970 because of abdominal pain.

She was severely anaemic ( $\mathrm{Hb} 6.4 \mathrm{~g} \%$ ), and pre $-\frac{3}{3}$ sented with signs of peritoneal irritation. An intra abdominal haemorrhage due to rupture of a vascular. tumour was suspected. In spite of repeated bloof transfusions and other supportive treatment, the patient died.

\section{Necropsy Findings}

On postmortem examination the following pertinent changes were observed. The right breast area showed? a tumour mass with a violet haematoma-like dis colouration. On section it was about $12 \mathrm{~cm}$ at its greatest diameter, had ill-defined, irregular borders $N$ and a spongy, haemorrhagic appearance with vascular spaces. The tumour was adherent to the skin, but not to the fascia of the pectoral muscle The liver was enlarged weighing 1,800 g. Beneath the capsule there were scattered multiple minute? reddish-black vesicles. Sections showed a 'Swisso cheese' appearance with many vascular spaces o $\overline{\bar{B}}$ various sizes (Fig. 1). The spleen weighed $520 \mathrm{~g} \overparen{\cap}$ and its external surface and sections disclosed vas $\mathbb{D}$ cular spaces similar to those in the breast anff 


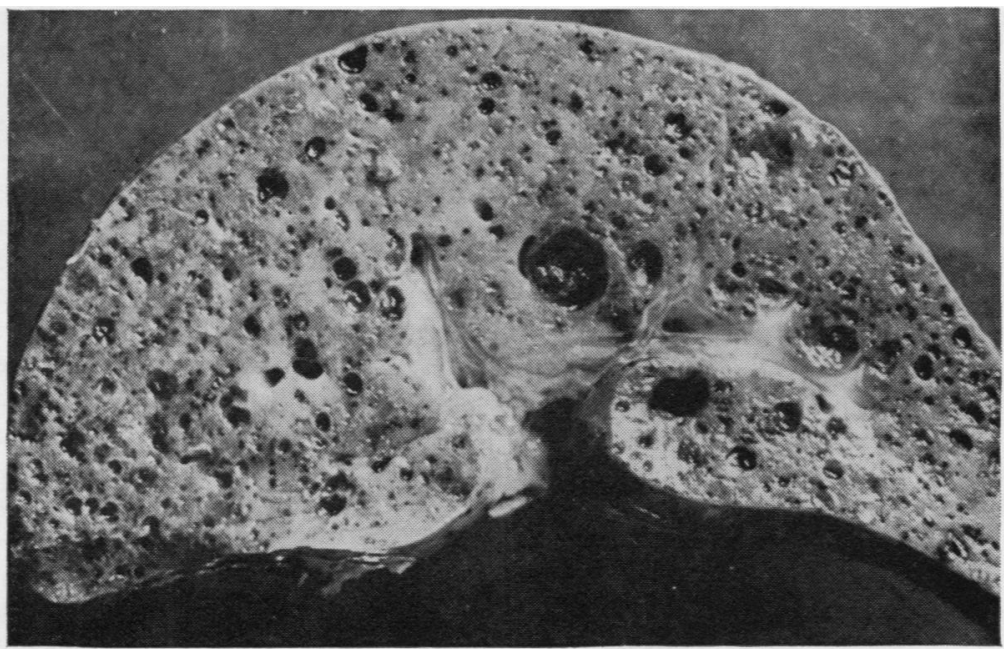

Fig. 1 Liver section showing 'Swiss-cheese' appearance of the vascular tumour.

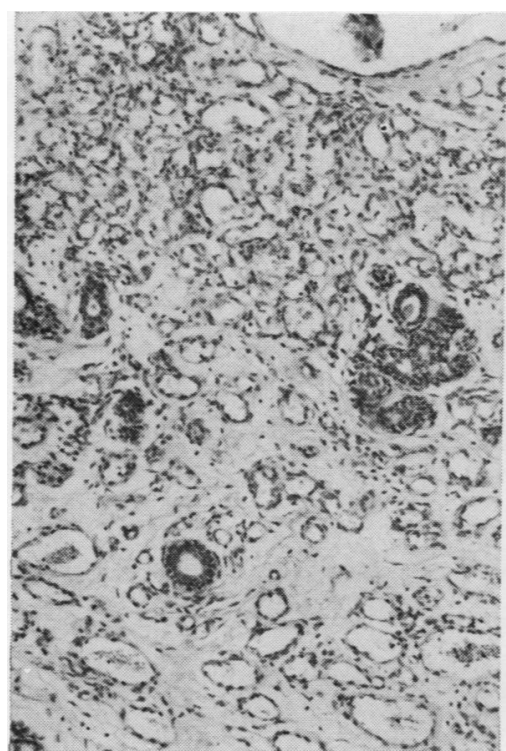

Fig. 2.

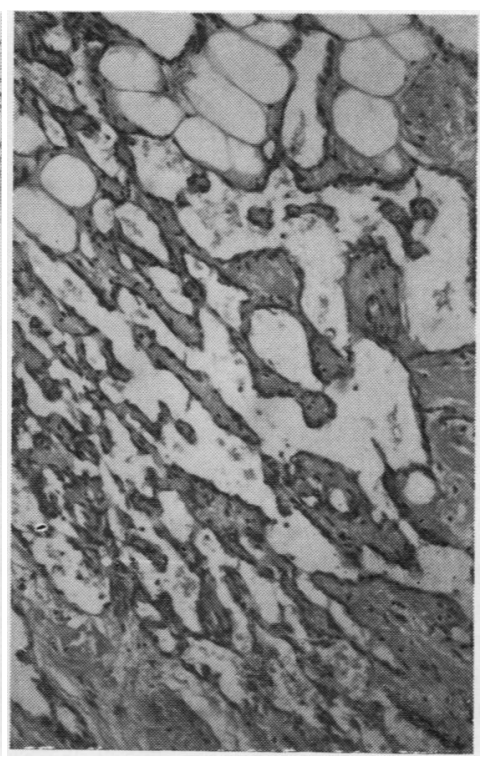

Fig. 3.

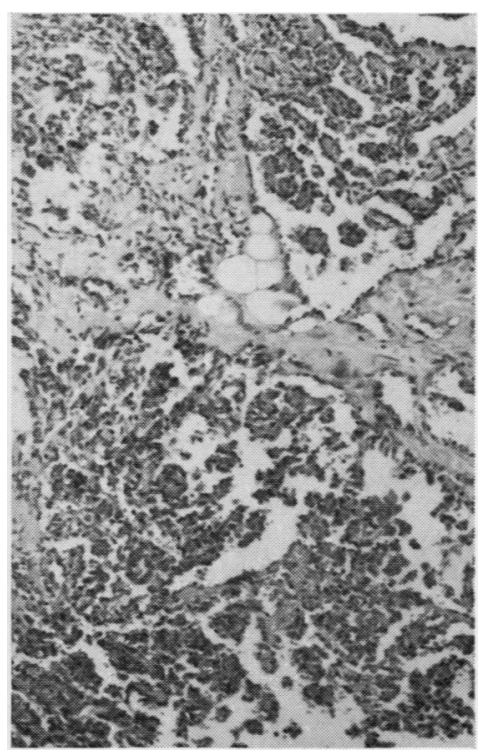

Fig. 4.

Fig. 2 Area of angiomatous breast tumour of benign histological appearance (haematoxylin and eosin $\times 40$ ).

Fig. 3 Part of the breast tumour showing anastomosing vascular channels (haematoxylin and eosin $\times 100$ ).

Fig. 4 Breast tumour with papillary growth into vascular spaces (haematoxylin and eosin $\times 100$ ). 
liver. Some of those had ruptured into the abdominal cavity, where about 31 of a haemorrhagic fluid and a few blood clots were present. A few small similar metastases were also found in the lungs.

Histological examination of the first breast biopsy showed a tumour composed of blood spaces lined by benign-appearing endothelial cells (Fig. 2). A few anastomosing channels were lined by endothelial cells with somewhat larger and more hyperchromatic nuclei (Fig. 3). In the necropsy material atypical tumour cells had proliferated with mitotic activity and papillary projections narrowing the lumen of the vascular spaces (Fig. 4), while some foci still retained the appearance of a benign haemangioma. The cells were confined within a fine reticulin network. The final diagnosis was a typical haemangiosarcoma.

\section{Discussion}

Proliferating angiomatous lesions are very common, but it is doubtful if they are true tumours or vascular malformations. Some authors are reluctant to admit the existence of malignant angioblastic neoplasms, preferring to consider them as vasoformative variants of mesenchymoma (Tasker, 1958). Others believe that in the breast these lesions arise in perilobular angiomas (McDivitt et al, 1968). The behaviour of these lesions is variable. Haemangiosarcoma of bone runs a protracted clinical course and the patients have a long survival period after operation (Hartmann and Stewart, 1962). Haemangiosarcoma of the breast is a highly malignant tumour (Evans, 1968) producing a fatal outcome regardless of the mode of therapy. This tumour is more frequent in the reproductive period of life. This fact, and the relatively frequent assoziation with pregnancy (Batchelor, 1958/59; Enticknap, 1946; McClanahan and Hogg, 1954; Tibbs, 1953), suggests local hormonal stimulation leading to malignant transformation of the vascular endothelium (Shore, 1957). A history of trauma preceding the development of the tumour has been described in several cases (McClanahan and Hogg, 1954; Patrick, Jarvie, and Miln, 1957; Steingaszner et al, 1965) but no definite relation has ever been established. Radioactive materials like Thorotrast are known to induce neoplastic changes, among them haemangiosarcoma (Casper, 1967).

Microscopically the haemangiosarcoma shows a network of multiple atypical capillaries and anastomoses lined by swollen anaplastic endothelial cells. In some cases(Mackenzie, 1961; Steingaszner et al, 1965) the tumour appears at the onset to be a benign haemangioma and the gradual transition to a malignant tumour is observed only in the recurrences. It is important to stress this behaviour 9 because, as also happened in the present case, the tumour may be initially diagnosed erroneously as a benign lesion.

Another important question is whether multiple $\stackrel{\mathbb{D}}{\circ}$ foci of this lesion are the result of metastases from a primary localized focus or whether these arise through a malignant transformation of multiple angiomatous malformations (Patrick et al, 1957). In the present case the angiomatous tumour in the breast definitely preceded all the other lesions. The $\frac{\Omega}{8}$ clinical history and the scanning performed three in months before death did not demonstrate any vascular lesion in the liver. Furthermore primary of haemangiosarcoma of the liver is frequently asso- ${ }_{0}^{\circ}$ ciated with haemopoietic foci, possibly formed by 은 differentiation of Kupfer cells into haemopoietic $\vec{A}$ stem cells (Baker, Paget, and Davson, 1956). In the $\mathcal{D}$ present case such haemopoietic foci were not found, $\frac{\mathbb{O}}{\mathbb{O}}$ and contributes to our assumption that the hepatic vascular tumours found at necropsy were metastases which occurred in the last months of the patient's life.

We are grateful to Mrs $\mathrm{K}$. Norton and $\mathrm{Mr} \mathrm{J}$ Schachter for the photographs.

References

Baker, H. De C., Paget, G. E., and Davson, J. (1956). Haemangioendothelioma (Kupfer cell sarcoma) of the liver. J. Path. Bact., 72, 173-182.

Batchelor, G. B. (1958-59). Haemangioblastoma of the breast associated with pregnancy. Brit. J. Surg., 46, 647-649.

Casper, J. (1967). Peritoneal hemangioendotheliomatosis after salpingography with Thorotrast. Ann. N.Y. Acad. Sci., 145, 798805 .

Enticknap, J. B. (1946). Angioblastoma of the breast complicating pregnancy. Brit. med. J., 2, 51 .

Evans, R. W. (1968). Histological Appearances of Tumours, 2nd ed Livingstone, Edinburgh and London.

Gulesserian, H. P., and Lawton, R. L. (1969). Angiosarcoma of the breast. Cancer (Philad.), 24, 1021-1026.

Hartmann, W. H., and Stewart, F. W. (1962). Hemangioendothelioma of bone. Unusual tumour characterized by indolent course. Cancer (Philad.), 15, 846-854.

Mackenzie, D. H. (1961). Angiosarcoma (hemangioblastoma) of the breast. Brit. J. Surg., 49, 140-143.

McClanahan, B. J., and Hogg, L., Jr. (1954). Angiosarcoma of the breast. Cancer (Philad.), 7, 586-594.

McDivitt, R. W., Stewart, F. W., and Berg, J. W. (1968). Tumours of the breast. In Atlas of Tumor Pathology, 2nd series, Fasc. 2, pp. 127-130. Armed Forces Institute of Pathology, Washington, D.C.

Patrick, R. S., Jarvie, J., and Miln, D. C. (1957). Hemangioblastoma of breast: a report of 3 cases. Brit. J. Surg., 45, 188-193.

Shore, J. H. (1957). Haemangiosarcoma of the breast. J. Path. Bact., 74, 289-293.

Steingaszner, L. C., Enzinger, F. M., and Taylor, H. B. (1965) Hemangiosarcoma of the breast. Cancer (Philad.), 18, 352-361.

Tasker, R. G. (1958). Haemangio-endothelioma of the spleen and liver. J. clin. Path., 11, 142-145.

Tibbs, D. (1953). Metastasizing haemangiomata. A case of malignant hemangioendothelioma. Brit. J. Surg., 40, 465-470. 